\title{
IN SITU TEM STUDIES OF SINTERING OF Pd/ALUMINA CATALYSTS
}

\author{
R.-J. Liu ${ }^{1}$, P. A. Crozier ${ }^{1}$, C. M. Smith ${ }^{2}$, D. A. Hucul ${ }^{3}$, J. Blackson ${ }^{3}$ and G. Salaita ${ }^{4}$ \\ ${ }^{1}$ Center for Solid State Science, Arizona State University, Tempe, AZ 85287 \\ ${ }^{2}$ Hydrocarbons and Energy R\&D, the Dow Chemical Company, Freeport, TX 77541 \\ ${ }^{3}$ Analytical Sciences Corporate R\&D, the Dow Chemical Company, Midland, MI 48667 \\ ${ }^{4}$ South Charleston Technical Center, the Dow Chemical Company, South Charleston, WV 25303
}

$\mathrm{Pd} /$ alumina catalysts are widely used for hydrogenation of alkynes [1]. However, during the reaction, the catalysts are gradually deactivated by hydrocarbon (green oil) build-up and eventually need to be regenerated. The regeneration process includes stripping hydrocarbon by steam and air, then reducing the catalysts with hydrogen. The regenerated catalysts usually show less activity and different selectivity compared with the fresh catalysts. This phenomenon is often attributed to the decrease in the active metal surface area caused by sintering during the regeneration process [2]. To study the sintering mechanism, we used environmental transmission electron microscopy (E-TEM) to observe the behavior of $\mathrm{Pd}$ particles in the fresh and used catalysts in oxidizing environments.

Pd was deposited on alumina (a combination of $\alpha-$ and $\delta-\mathrm{Al}_{2} \mathrm{O}_{3}$ ) by an impregnation method using nitrates as precursors. The catalysts $(0.1 \mathrm{wt} \% \mathrm{Pd})$ were calcined in flowing air at $500^{\circ} \mathrm{C}$ for 2 hours and then reduced in pure $\mathrm{H}_{2}$ at $130^{\circ} \mathrm{C}$ for 1 hour to activate. Pd particles in the fresh catalysts (Fig. 1a) usually have hemispherical or elongated shape. Experiments showed that in a vacuum or steam environment, particle shape change and sintering would become noticeable only when the catalysts were heated above $500^{\circ} \mathrm{C}$. Figs. $1 \mathrm{~b}$ and $\mathrm{c}$ show the microstructure of the catalysts (same area as in Fig. 1a) after heated in 500 mTorr of steam at $700^{\circ} \mathrm{C}$ for 4 and 7 hours, respectively. Particles were observed to sinter through two traditional mechanisms: (a) ripening and (b) migration and coalescence, with the ripening mechanism dominating.

The hydrogenation of acetylene over the prepared catalysts was performed in an industrial reactor. The catalysts were kept on-stream for 124 hours at a temperature varied from 110 to $145^{\circ} \mathrm{F}$ to keep a constant acetylene conversion level. CBED and EELS analysis revealed that in the used catalysts, most of the $\mathrm{Pd}$ particles were lifted from the alumina surface and embedded in the amorphous hydrocarbon particles (Figs. 2a and 3a). Clustering of Pd particles is also revealed in this images. When heated in 500 mTorr of steam at $350^{\circ} \mathrm{C}$, it was observed that the clusters of particles fused first, then particles would move on the hydrocarbon and fuse with other particles. As these particles moved, they left light-contrast tracks behind, suggesting that hydrocarbon was stripped catalytically. Figs. $2 \mathrm{~b}$ and $\mathrm{c}$ shows the microstructure of the used catalysts after heating in steam for 4 and 7 hours, respectively. The light-contrast tracks and particle sintering are revealed. However, steam could not strip hydrocarbon without the help of Pd particles, and the catalytic stripping process would terminate after 4 hours of heat treatment. The reason for termination is still under investigation. When heated in 500 mTorr of air at $350^{\circ} \mathrm{C}$, similar sintering behavior was observed, but even after particles reached the surface of alumina support and stopped moving, the remaining hydrocarbon could still be stripped by air (see Fig. 3). Compared with our observation of particle behavior in the fresh catalysts heated in the same environment, catalytic stripping of hydrocarbon can make the Pd particles move around at much lower temperature; and 
although the readout temperature from the thermocouple of the specimen holder was $350^{\circ} \mathrm{C}$, fusion of $\mathrm{Pd}$ particles in the used catalysts suggests that during hydrocarbon stripping, the temperature around the $\mathrm{Pd}$ particles might reach at least $500^{\circ} \mathrm{C}$.

\section{References}

[1] J. Gislason et al., J. Phys. Chem. A106 (2002) 767.

[2] T. B. Lin and T. C. Chou, Ind. Eng. Chem. Res. 34 (1995) 128.

[3] Funding was provided by the Dow Chemical Company.
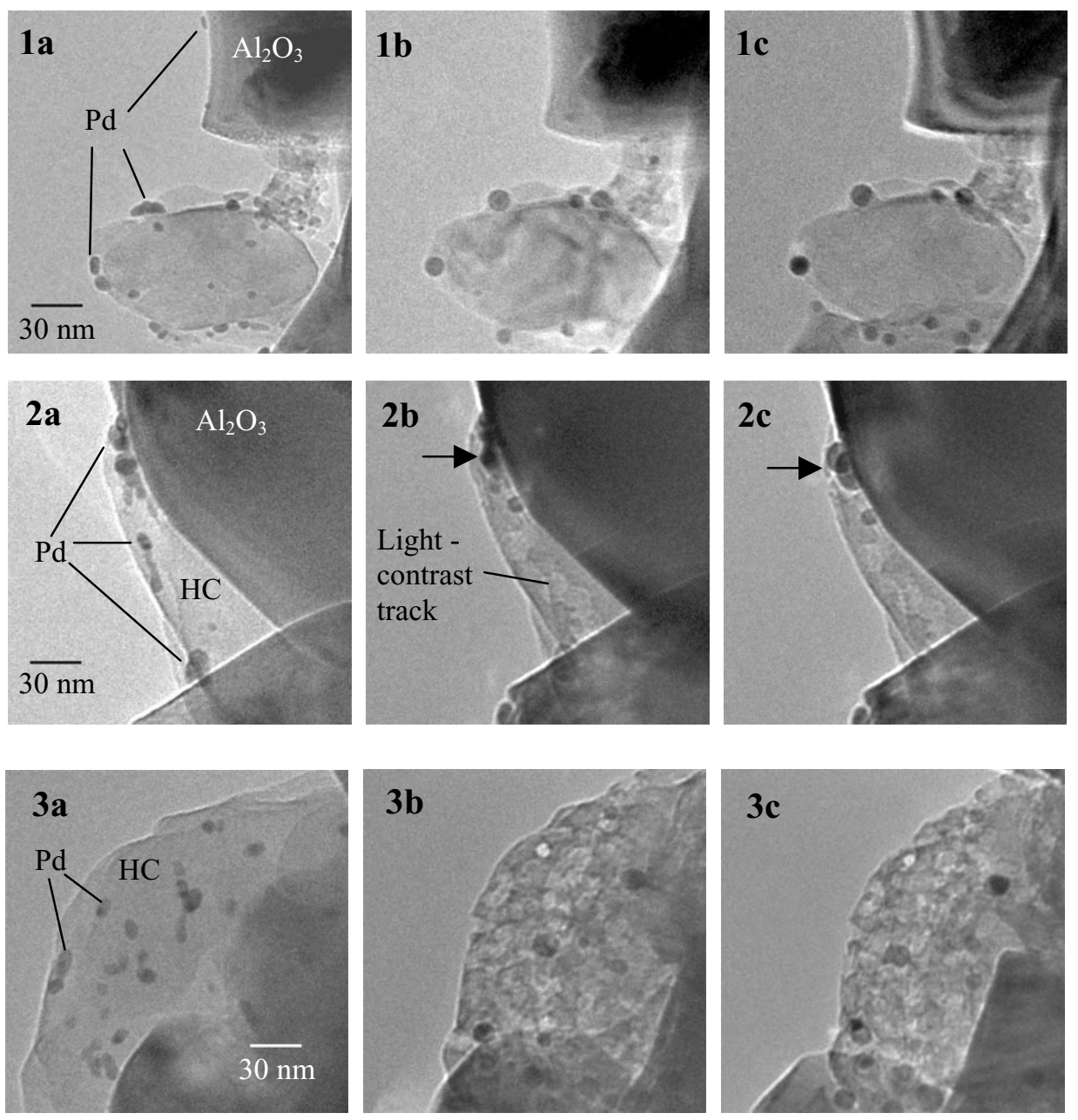

FIG. 1. TEM images of the fresh catalysts in the as-received condition at room temperature (a) and after heated in $500 \mathrm{mTorr}$ of steam at $700^{\circ} \mathrm{C}$ for 4 (b) and 7 hours (c).

FIG. 2. TEM images of the used catalysts in the as-received condition at room temperature (a) and after heated in 500 mTorr of steam at $350^{\circ} \mathrm{C}$ for 4 (b) and 7 hours (c). HC means hydrocarbon. Arrows indicate particle sintering.

FIG. 3. TEM images of the used catalysts in the as-received condition at room temperature (a) and after heated in $500 \mathrm{mTorr}$ of air at $350^{\circ} \mathrm{C}$ for 4 (b) and 7 hours (c). 